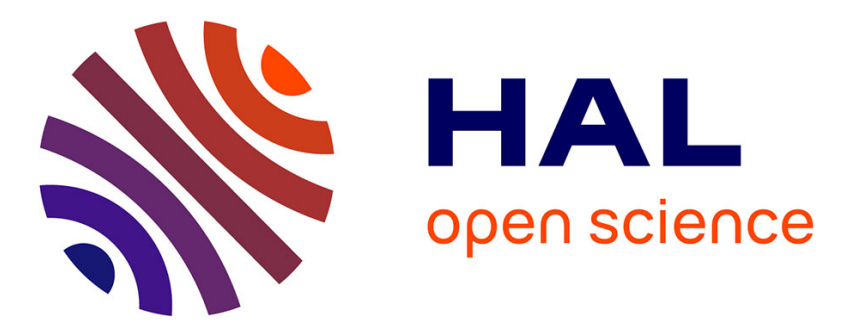

\title{
Morphological analysis of microcellular PP produced in a core-back injection process using chemical blowing agents and gas counter pressure
}

José Antonio Reglero Ruiz, Michel Vincent, Jean-François Agassant, Aurore Claverie, Sébastien Huck

\section{To cite this version:}

José Antonio Reglero Ruiz, Michel Vincent, Jean-François Agassant, Aurore Claverie, Sébastien Huck. Morphological analysis of microcellular PP produced in a core-back injection process using chemical blowing agents and gas counter pressure. Polymer Engineering and Science, 2015, 55 (11), pp.24652473. 10.1002/pen.24136 . hal-01182895

\section{HAL Id: hal-01182895}

https://hal-mines-paristech.archives-ouvertes.fr/hal-01182895

Submitted on 16 Oct 2015

HAL is a multi-disciplinary open access archive for the deposit and dissemination of scientific research documents, whether they are published or not. The documents may come from teaching and research institutions in France or abroad, or from public or private research centers.
L'archive ouverte pluridisciplinaire HAL, est destinée au dépôt et à la diffusion de documents scientifiques de niveau recherche, publiés ou non, émanant des établissements d'enseignement et de recherche français ou étrangers, des laboratoires publics ou privés. 


\title{
Morphological analysis of microcellular PP produced in a core-back injection process using chemical blowing agents and gas counter pressure
}

\author{
José Antonio Reglero Ruiz ${ }^{1}$, Michel Vincent ${ }^{1}$, Jean-François Agassant ${ }^{1}$, Aurore Claverie ${ }^{2}$, \\ Sébastien Huck ${ }^{2}$ \\ ${ }^{1}$ MINES ParisTech - Centre de Mise en Forme des Matériaux (CEMEF) \\ UMR CNRS 7635 \\ 1, rue Claude Daunesse, CS 10207, 06904 - Sophia Antipolis Cedex, France. \\ ${ }^{2}$ MECAPLAST France, BP 12 ZI La Mode, 01580 Izernore, France.
}

\begin{abstract}
A complete experimental analysis of the microcellular injection process using Chemical Blowing Agents (CBA) with Gas Counter Pressure (GCP) and core-back expansion is presented. Three different types of polypropylene, neat and charged, were mixed with two different CBAs and injected into a plate mold with varying process parameters. First, an exhaustive cartographical mapping of the plate morphology is analyzed. In a second step, the relation between injection parameters and the resulting morphology is investigated. The results show that injection time affects the cellular structure. The formulation, especially the type of chemical foaming agent, controls the average bubble radius. Compared to classical injection process, the use of CBAs, combined to Gas Counter Pressure and core-back process, allows obtaining parts with good surface aspect, more homogeneous cellular structures and smaller bubble radius.
\end{abstract}

\section{1 - Introduction}

The commercial and industrial interest in polymeric structural foams has been increasing in the last years, due to the combination of good mechanical properties and weight reduction. Especially in injection molded parts, the foaming process provides several advantages, such as good surface aspect, good dimensional stability and the reduction of the process time [1]. The injection foaming process leads to core-shell foamed structures with closed outer skins and a foamed core [2,3], leading to correct surface quality of molded parts. The thickness of the solid outer skins (without bubbles) can be controlled by adjusting the cooling process (such as the mold temperature) [4,5]. Since the viscosity of the polymer/gas mixture is lower than the viscosity of the polymer melt itself, the parts can be injection molded with a lower pressure. Moreover, the cell growth mechanism favors the part packing and reduces residual stresses. Two kinds of injection foaming processes have been developed:

The first one consists in introducing a physical blowing agent (PBA), usually $\mathrm{N}_{2}$ or $\mathrm{CO}_{2}$, directly into the barrel in a supercritical fluid state (SCF), in proportions around $2 \%$ in weight $[6,7]$. The injection machine must be modified, resulting in an initial increase of the production costs. The Mucell囚 process [8] is now largely used to produce injected foamed parts.

The second process uses chemical blowing agents (CBA) $[9,10,11]$. The foaming agent is added in the form of pellets to the feeder of the injection machine, in a proportion between 1 
and $2 \%$ in weight. The foaming agent employed for polypropylene injection processes is a low density polyethylene charged with a percentage of inorganic compounds, such as citric acid or sodium bicarbonate, which decompose at temperatures close to the melting point of the polymer, generating the gas, mainly $\mathrm{CO}_{2}$ and water vapor. As in the PBA process, the polymer with the solubilized gas is then injected into the mold, and foaming occurs by the depressurization and cooling during the injection process. The main advantage of CBA process compared to PBA is that no modification of the injection machine is needed, because the foaming agent is directly added into the barrel through the hopper. On the other hand, a more accurate control of the injection parameters, such as injection time or mold temperature, is required to obtain optimal injection foamed parts. This paper is focused on CBA.

The core-back expansion process which is investigated in this paper derives from the classical injection molding process, where a command module is added to control the movement of the mobile part of the mold. After mold filling and a short packing step the mold is accurately opened to quickly increase the cavity volume and rapidly reduce pressure. The sudden pressure drop enhances bubble nucleation and achieves a fine cell structure within the polymer foam. Thus, core-back foam injection molding is effective in achieving a high expansion ratio with uniform fine cell structure.

One of the main problems associated with foam injection molding is related to foam evolution during filling stage. As foaming starts during mold filling this leads to inhomogeneous foam structures. This has been observed by Villamizar and Han [12]. The resulting products usually have severe surface defects such as swirl marks and lack of smoothness [13,14]. The introduction of a gas counter pressure (GCP) has been recently proved to improve the surface quality of molded parts. In this process, after mold closing, the mold cavity is pressurized around $2 \mathrm{MPa}$, and the melt is injected in the mold cavity in this high-pressure environment. This reduces melt foaming during mold filling and the fracture of the cells, and the swirl marks on the surface of plastic parts are decreased or eliminated.

Bledzki et al. [15] analyzed the influence of GCP process on cell size and mechanical properties of microcellular injection molded parts for different materials, using both Chemical Blowing Agents (CBA) and Physical Blowing Agents (PBA). Kotzev et al. [16] analyzed the morphology of foamed LDPE/PP blends injected with a counter pressure process. Jahani et al. [17] analyzed the morphology and acoustical properties of open-cell foams using coreback and high GCP values (up to $10 \mathrm{MPa}$ ). Also Pantani et al. [18] analyzed the foaming of PLA using core-back and GCP techniques, with a complete mapping of the morphology of the sample. However, only the mold temperature is varied, and the rest of injection parameters are unchanged. Chen et al. [19,20,21] have deeply analyzed the effect of GCP parameters on the surface quality and morphology of several microcellular injection molded parts, using a PBA process, but without core-back foam injection molding. Finally, Li et al. [22] deeply analyzed the effect of the GCP values on the surface quality and morphology of microcellular injected polystyrene foams. All these studies demonstrate the efficiency of the introduction of the GCP to reduce the surface defects.

There are few experimental studies of the foam morphology obtained in core-back injection process combined with GCP process. The present work is focused on the morphological observation and quantification of molded parts with pure and reinforced polypropylene using 
different Chemical Blowing Agents [23] and a core-back expansion molding process. Several injection parameters, especially the gas counter pressure, have been tested. First, a detailed analysis of a sample will be carried out in order to check the variability of the morphology within the sample. Then a set of injection tests will be carried out and the morphology and surface aspect of the different samples and the role of the material and the injection parameters will be checked. Finally the way to produce homogeneous foaming structures with a good surface quality will be discussed.

\section{2 - Raw materials}

Three different impact polypropylenes were employed. The first one is a pure polypropylene (PP-1) with a melt flow index of $65 \mathrm{~g} / 10 \mathrm{~min}$ (ISO R1133), and a density of $0.91 \mathrm{~g} / \mathrm{cm}^{3}$ whereas the second one (PP-2) is filled with 7 wt. \% talc and the last one (PP-3) is filled with 12 wt. \% mineral charges ( 7 wt. \% talc and 5 wt. \% magnesium fibers of average length 30 $\mu \mathrm{m}$ and diameter $2 \mu \mathrm{m})$. Two different endothermic chemical blowing agents referred as CBA-1 and CBA-2 have been used. These foaming agents are polyethylene-based compounds. CBA-1 contains $35 \mathrm{wt}$. \% of citric acid and $35 \mathrm{wt}$ \% of sodium bicarbonate, and CBA-2 contains 70 wt. \% of sodium bicarbonate (wt. \% respect to the polyethylene matrix). In the following, CBA refers to the compound and not to the reactive elements only. The decomposition reactions of both CBAs are described in our previous work [23].

Thermal characterization was carried out using a Perkin Elmer equipment (model DSC 400), under nitrogen atmosphere at a heating rate of $70^{\circ} \mathrm{C} / \mathrm{min}$. This value was chosen to assure a similar heating rate as in the plasticization system of the injection tests. This allows determining the polypropylene fusion temperature and the decomposition temperatures of each reaction of the reactive elements included in the CBA pellets. A detailed description of the results is also included in our previous work [23]. The melting temperature of the polypropylene matrix is between $160{ }^{\circ} \mathrm{C}$ and $170{ }^{\circ} \mathrm{C}$ and the melting temperature of the polyethylene in the CBAs is around $100^{\circ} \mathrm{C}$. The decomposition reaction temperature of the citric acid in CBA-2 is around $215^{\circ} \mathrm{C}$. For the CBA-1, the coupled reaction of the sodium bicarbonate and the citric acid is between $200^{\circ} \mathrm{C}$ and $220^{\circ} \mathrm{C}$. This reaction is dominant at the high heating rates (above $20^{\circ} \mathrm{C} / \mathrm{min}$ ), encountered during the plasticization step in the screw-barrel unit. All the decomposition reactions of the CBAs start after the polypropylene fusion, which assures that the gas obtained from the CBAs can be diluted in the melted matrix.

The crystallization behavior of the PP compounds was also analyzed using DSC tests. After a first heating ramp from room temperature to $275^{\circ} \mathrm{C}$, polymers were cooled down at two different rates $\left(70{ }^{\circ} \mathrm{C} / \mathrm{min}\right.$ and $\left.5^{\circ} \mathrm{C} / \mathrm{min}\right)$, to evaluate the effect of the cooling rate on the crystallization temperature. The results for PP-2 and PP-3 show a small influence of the talc charges, with crystallization temperatures about $5^{\circ} \mathrm{C}$ lower than the data obtained for neat PP (PP-1). PP-1 presents a crystallization temperature around $125^{\circ} \mathrm{C}$ when cooling rate is $70^{\circ} \mathrm{C} / \mathrm{min}$, and $155^{\circ} \mathrm{C}$ when cooling rate is $5^{\circ} \mathrm{C} / \mathrm{min}$. 
TGA measurements were carried out using a Mettler Toledo TGA 1 equipment under nitrogen atmosphere and a heating rate of $70{ }^{\circ} \mathrm{C} / \mathrm{min}$ to determine the quantity of gas released by the reactive elements in the CBA pellets (figure 1). The relative weight loss refers to the original weight of the granule containing $30 \mathrm{wt}$. \% of polyethylene and $70 \mathrm{wt} . \%$ of reactive elements. This loss is associated to the gas escaping the sample, assuming that the pressure conditions do not allow any gas dissolution in the polyethylene. In the case of CBA-2, the decomposition reaction of citric acid begins at $215^{\circ} \mathrm{C}$ and ends around $300{ }^{\circ} \mathrm{C}$, with a weight percentage of gas created about $35 \%$. The CBA-1 presents a decomposition reaction which begins around $200{ }^{\circ} \mathrm{C}$. The citric acid decomposition reaction is coupled with the sodium bicarbonate reaction, as it can be observed in the small change in the slope about $220^{\circ} \mathrm{C}$. The maximum quantity of gas generated at the end of the decomposition reactions is about 28 wt. $\%$ at $300^{\circ} \mathrm{C}$. In both cases, the $\mathrm{PE}$ decomposition begins at $450^{\circ} \mathrm{C}$. The TGA results are in qualitative agreement with the DSC measurements, with a reaction occurring at temperature lower for CBA-1 than for CBA-2.

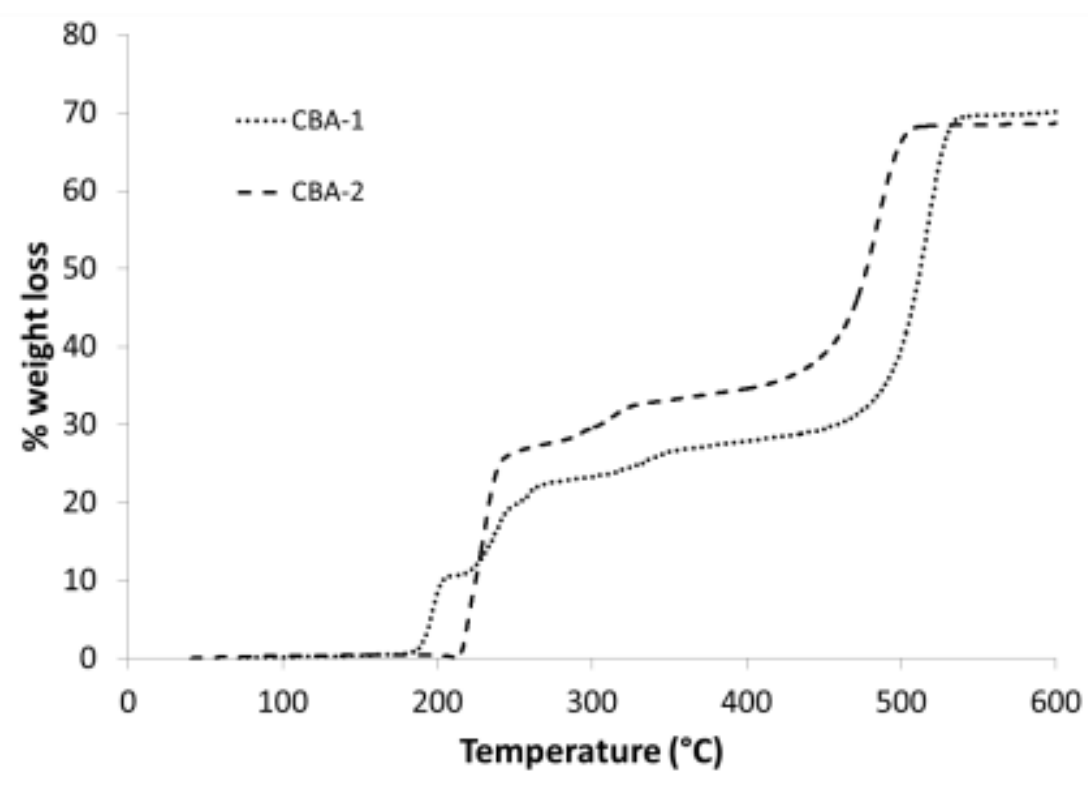

Figure 1 - TGA curves of the CBA particles

(Heating ramp $70^{\circ} \mathrm{C} / \mathrm{min}$ )

Rheological characterization of raw materials was carried out at $190^{\circ} \mathrm{C}, 200{ }^{\circ} \mathrm{C}, 210^{\circ} \mathrm{C}$ and $220{ }^{\circ} \mathrm{C}$, using a TA-Ares rotational rheometer. Tests were performed in dynamic mode between parallel plates (diameter $25 \mathrm{~mm}$, gap $2 \mathrm{~mm}$ ) with frequencies $w$ between $0.1 \mathrm{~s}^{-1}$ and $100 \mathrm{~s}^{-1}$. Viscosity values at $\omega=0.1 \mathrm{~s}^{-1}$ are $285 \mathrm{~Pa} \cdot \mathrm{s}, 513 \mathrm{~Pa} \cdot \mathrm{s}$ and $678 \mathrm{~Pa} \cdot \mathrm{s}$ for the PP-1, PP2 and PP-3, respectively (measured at $220{ }^{\circ} \mathrm{C}$ ). It is reasonable to assume that during the foaming process bubble growth speed is low enough so that viscosity remains in that regime.

\section{3 - Injection tests}

Injection tests were carried using an ENGEL machine of 80 tons clamping force, with a maximal injection capacity of $150 \mathrm{~cm}^{3}$. It is equipped with a shut-off nozzle. The screw diameter $D$ was $32 \mathrm{~mm}$, with $L / D=24$ ( $L$ is the screw length). Polymer pellets were introduced in the hopper with $2 \mathrm{wt}$ \% of CBA. Rectangular plates were molded, (width 95 $\mathrm{mm}$ and length $165 \mathrm{~mm}$ ). The gate is located close to the middle of the plate width. The initial 
plate thickness $h_{0}$ during mold filling is then suddenly increased reaching a final thickness of $2.5 \mathrm{~mm}$ after foaming. The total volume of the sample including sprue and gate was about 36 $\mathrm{cm}^{3}$. The injection temperature is $230^{\circ} \mathrm{C}$.

Filling flow rate and gas counter pressure values (GCP) were varied in order to analyze their influence on the samples morphology. It is important to say the GCP values are nominal, and the selected values can present some variations. Two groups of samples were injected. In the first group, 18 samples were obtained, employing the three polypropylenes and the two CBAs. Only the gas counter pressure has been varied with a fixed injection time of $0.4 \mathrm{~s}$. In the second group, samples of PP-3 + CBA-1 were used with an injection time varying from $0.7 \mathrm{~s}$ to $1.5 \mathrm{~s}$. Table 1 shows the injection parameters and formulation of all the tests. $\mathrm{A}$ minimum of three plates for each condition were analyzed to assure a good reproducibility of the morphology results.

\begin{tabular}{|c|c|c|c|c|}
\hline Test & Material & $C B A$ & $\begin{array}{c}\text { Gas Counter Pressure } \\
\text { (MPa) }\end{array}$ & $\begin{array}{c}\text { Injection time } \\
\text { (s) }\end{array}$ \\
\hline $1-1$ & \multirow{6}{*}{ PP-1 } & \multirow{3}{*}{1} & 1 & \multirow{6}{*}{0.4} \\
\hline $1-2$ & & & 1.5 & \\
\hline $1-3$ & & & 2.5 & \\
\hline $1-4$ & & \multirow{3}{*}{2} & 0.5 & \\
\hline $1-5$ & & & 1 & \\
\hline $1-6$ & & & 1.5 & \\
\hline $1-7$ & \multirow{6}{*}{ PP-2 } & \multirow{3}{*}{1} & 0.8 & \multirow{6}{*}{0.4} \\
\hline $1-8$ & & & 1.5 & \\
\hline $1-9$ & & & 2.5 & \\
\hline $1-10$ & & \multirow{3}{*}{2} & 0.5 & \\
\hline $1-11$ & & & 1 & \\
\hline $1-12$ & & & 1.5 & \\
\hline $1-13$ & \multirow{6}{*}{ PP-3 } & \multirow{3}{*}{1} & 0.8 & \multirow{6}{*}{0.4} \\
\hline $1-14$ & & & 1.5 & \\
\hline $1-15$ & & & 2.5 & \\
\hline $1-16$ & & \multirow{3}{*}{2} & 0.5 & \\
\hline $1-17$ & & & 1 & \\
\hline $1-18$ & & & 1.5 & \\
\hline $2-1$ & \multirow{4}{*}{ PP-3 } & \multirow{4}{*}{1} & \multirow{4}{*}{1.5} & 0.7 \\
\hline $2-2$ & & & & 0.9 \\
\hline $2-3$ & & & & 1.2 \\
\hline $2-4$ & & & & 1.5 \\
\hline
\end{tabular}

Table 1 - Injection parameters and formulation of all the injection tests

The percentage of gas created at $230^{\circ} \mathrm{C}$ estimated from the TGA curves is about $28 \%$ for the CBA-1 and $35 \%$ for the CBA-2. For a value of 2 wt. \% added of each CBA into the hopper, $0.02 \mathrm{~g}$ of $\mathrm{CBA}$ are introduced per $\mathrm{g}$ of $\mathrm{PP}$, which gives a relative value of gas between $0.0056 \mathrm{~g}_{\mathrm{gas}} / \mathrm{g}_{\mathrm{PP}}$ for CBA-1 and $0.007 \mathrm{~g}_{\mathrm{gas}} / \mathrm{g}_{\mathrm{PP}}$ for CBA-2, respectively. Part of the gas generated corresponds to $\mathrm{H}_{2} \mathrm{O}$ vapor that after foaming and cooling remains in the samples 
as condensed water vapor. About $30 \%$ of all the gas generated corresponds to $\mathrm{H}_{2} \mathrm{O}$ vapor and the rest is $\mathrm{CO}_{2}$ [23]. The maximum quantity of diluted $\mathrm{CO}_{2}$ at the temperature and pressure conditions in the nozzle is about $0.05 \mathrm{~g}_{\mathrm{co} 2} / \mathrm{g}_{\mathrm{PP}}$, as it is demonstrated in the work of Lei et al. [24]. Thus, the quantity of gas generated in our injection process is well below the solubility limit. The residence time of the CBA-PP system in the plasticization unit before injection shot is much more important than the decomposition reaction time, and also the temperature of the plasticization unit is higher than the decomposition temperatures of both CBAs. So it can be assumed that the decomposition reactions are complete before mold filling starts and, according to the screw back pressure and shut-off nozzle, that all the generated gas is diluted in the molten polymer before injecting the material.

\section{4 - Morphology}

\section{1 - Detailed morphology cartography}

Samples were fractured at ambient temperature to assure a good contrast between solid and foamed regions. The fracture surfaces were observed with a scanning electron microscope Philips XL-30.

A morphological mapping of three plates injected in the conditions of test 1-15 (see table 1) was carried out. Cross sections in $(X, Z)$ or $X, Y)$ planes were observed as shown on the dashed line on Fig. 2. Results will be shown for 4 sections $A, B, C, D$ in the flow direction and $A^{\prime}, B^{\prime}, C^{\prime}$ ?D' perpendicular to it. and observed All the observations were performed in the center of each cross section. A good reproducibility of results was found in the three injected plates. Several morphological parameters were analyzed: the skin/core ratio, the bubble size distribution along the plate thickness and the bubble shape.

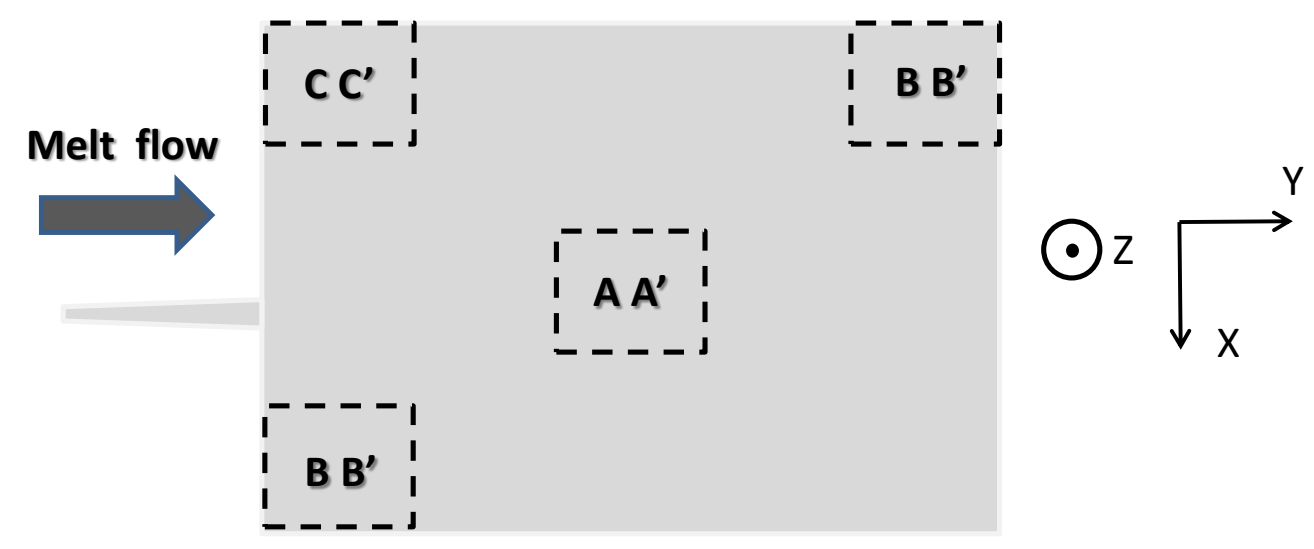

Figure 2 - Scheme of the observations carried out in the plate

\subsubsection{Analysis of the skin/core ratio}

All the samples observed show a dense skin surrounding a foam core. The thickness of each skin is around $350 \mu \mathrm{m}$. The skin/core ratio is about 0.28 , with a total sample thickness about $2.5 \mathrm{~mm}$. This skin thickness does not vary significantly for the injection parameters which have been tested (Table 1). This is obvious for test 1 , and in fact it does not change substantially for test 2 . 


\subsubsection{Analysis of the bubble size distribution and bubble shape along the plate thickness (test 1-15, table 1)}

Figure 3 presents two different micrographs taken in the perpendicular and parallel directions to injection flow. Samples were extracted from the center of the plate (samples A and A' according to figure 2). Bubble radius varies along the plate thickness between $90 \mu \mathrm{m}$ in the center of the sample and decreases to $20 \mu \mathrm{m}$ close to the solid skin. This gradient is observed in both observation directions. Bubbles are not spherical but slightly elongated in the thickness $(Z)$ direction. In the observations perpendicular to the flow direction (figure $3 a$ ), bubbles are elongated around $45^{\circ}$ with respect to the $\mathrm{Y}$ direction in the ( $\mathrm{Y}, \mathrm{Z}$ plane). Figure $3 \mathrm{~b}$ does not show such deformation.

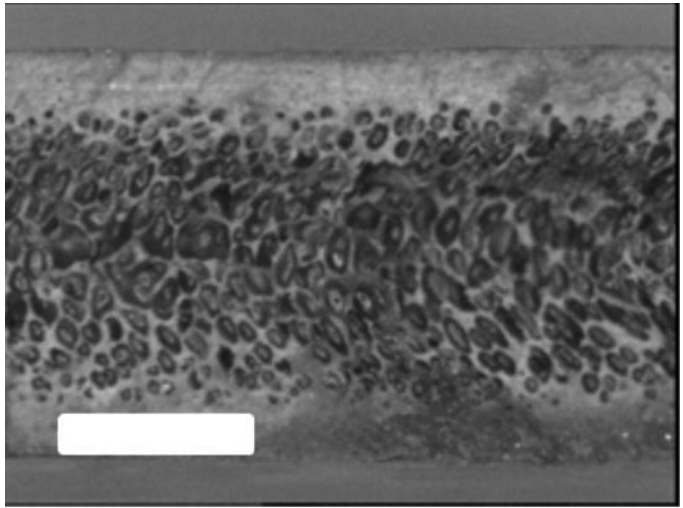

a)

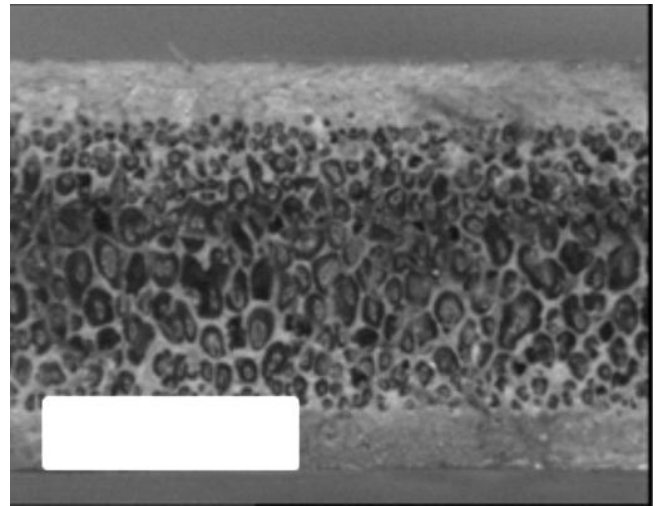

b)

Figure 3-Micrographs showing the bubble size distribution (bar scale $1 \mathrm{~mm}$ )

$$
\text { PP } 3(\text { PP+Talc+Fibers })+C B A 1
$$

a) Perpendicular to injection flow (sample $A$ )

b) Parallel to injection flow (sample $A^{\prime}$ )

The average bubble radius and cell density value were analyzed using the Image $\AA$ software [23] in five samples extracted from the center of the plate (samples $A$ and $A^{\prime}$ ) at different distances from the gate $(20,40,60,80,100 \%$ of the plate length). For each sample, five micrographs have been analyzed, thus 25 measurements in total. The software accounts for the number of bubbles in each image and the average radius. The number average radius $\bar{R}$ is calculated from equation (1):

$$
\bar{R}=\frac{\sum_{i=1}^{N} n_{i} R_{i}}{\sum_{i=1}^{N} n_{i}}
$$

where $\mathrm{N}$ represents the bubble count.

The total cell number $N_{c}$ in the sample was calculated using equation (2) [25], which accounts for the 3D extrapolation starting from a 2D image:

$$
N_{C}=\frac{6\left(1-\frac{\rho_{F}}{\rho_{P}}\right)}{\pi \bar{R}^{3}}
$$


$\rho_{P}$ corresponds to the solid polymer density $\left(0.91 \mathrm{~g} / \mathrm{cm}^{3}\right)$, and $\rho_{F}$ represents the foam core density, which is calculated from the volume fraction of solid skin $\phi$ and the sample density $\rho_{s}$ throughout the mixture's law (equation 3):

$$
\rho_{S}=\rho_{P} \cdot \emptyset+\rho_{F} \cdot(1-\emptyset)
$$

Table 2 presents the average morphological parameters obtained along the plate length for the injected plate of test 1-15.

\begin{tabular}{|c|c|c|c|c|}
\hline $\begin{array}{c}\text { Position } \\
\text { (\% of plaque } \\
\text { length) }\end{array}$ & $\begin{array}{c}\text { Bubble } \\
\text { count in } \\
\text { each image }\end{array}$ & $\begin{array}{c}\bar{R} \\
(\mu \mathrm{m})\end{array}$ & $\begin{array}{c}\rho_{\mathrm{F}} \\
\left(\mathrm{g} / \mathrm{cm}^{3}\right)\end{array}$ & $\begin{array}{c}\mathbf{N}_{\boldsymbol{c}} \\
\left(\mathrm{cm}^{-3}\right)\end{array}$ \\
\hline 20 & 207 & $81 \pm 11$ & 0.53 & $3.12 \cdot 10^{4}$ \\
\hline 40 & 204 & $86 \pm 12$ & 0.55 & $2.47 \cdot 10^{4}$ \\
\hline 60 & 181 & $91 \pm 13$ & 0.52 & $2.13 \cdot 10^{4}$ \\
\hline 80 & 197 & $84 \pm 12$ & 0.54 & $2.45 \cdot 10^{4}$ \\
\hline 100 & 168 & $101 \pm 26$ & 0.57 & $1.21 \cdot 10^{4}$ \\
\hline
\end{tabular}

Table 2 - Morphological parameters of one plate obtained along the plate length (test 1-15, see table 1)

Table 2 points out that the average radius (within the thickness) of the cellular structure is quite uniform along the plate. However at the front flow (100\% of volume filled) where the pressure is less important (equal to the GCP) bubbles have higher radius values (up to 100 $\mu \mathrm{m})$. In the solid outer skin, high magnification SEM reveals small bubbles with diameters between 100 and $500 \mathrm{~nm}$.

\subsubsection{Analysis of the bubble size and shape near the edges of the plate}

As seen in figure 2, three different regions of the plate were analyzed. Micrographs $B, C$ and D (figure 4) show the morphology perpendicular to the plate length and micrographs B', C' and D' (figure 5) show the morphology parallel to the plate length.

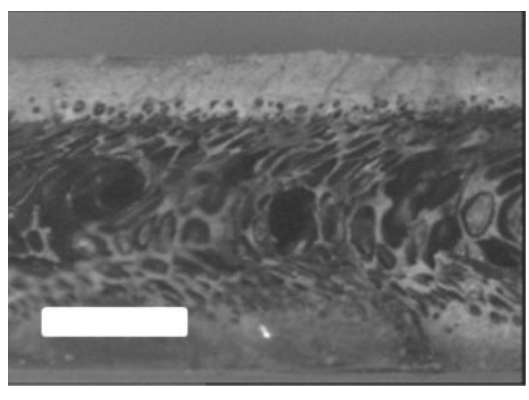

a)

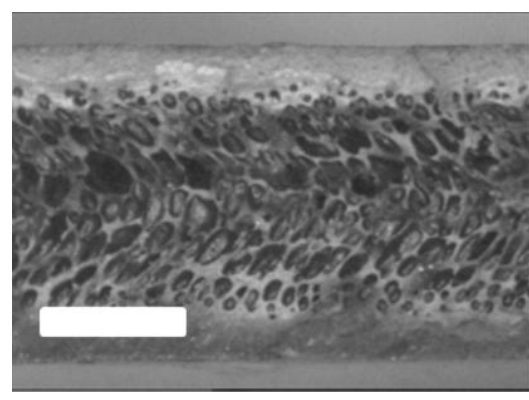

b)

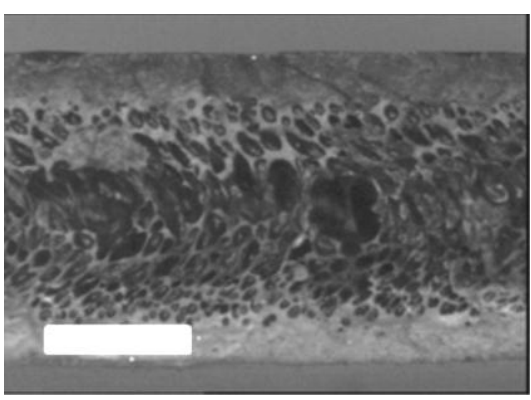

c)

Figure 4-Optical micrographs extracted from the cartography of the cellular structure perpendicular to plate length (bar scale $1 \mathrm{~mm}$ ) $P P 3(P P+$ Talc + Fibers $)+C B A 1$

a) Position $B$ b) Position $C$ c) Position $D$ 


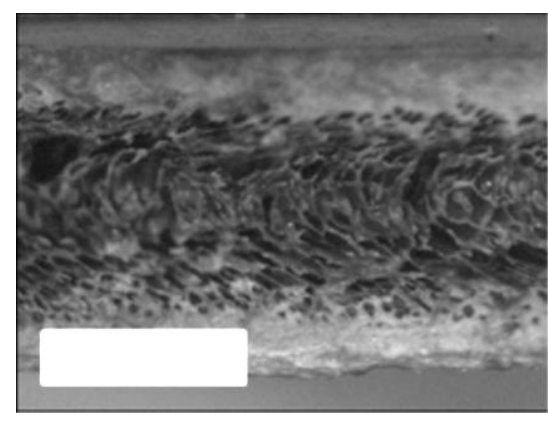

a)

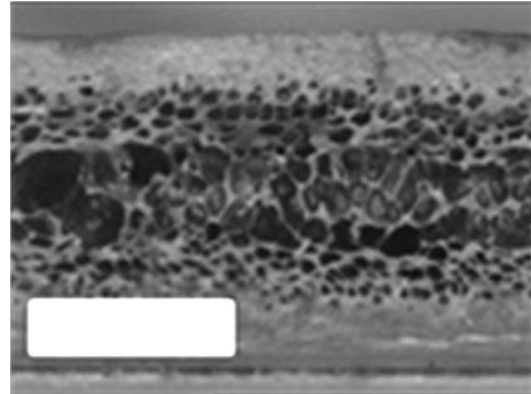

b)

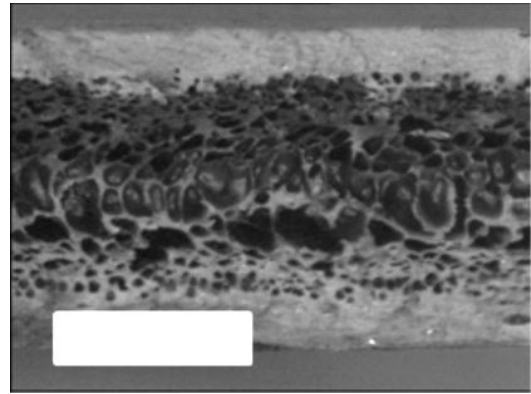

c)

Figure 5-Optical micrographs extracted from the cartography of the cellular structure parallel to plate length (bar scale $1 \mathrm{~mm}$ )

$P P 3$ (PP+Talc+Fibers) + CBA 1

a) Position B' b) Position C'c) Position D'

Micrographs B and B' show elongated bubbles in both directions (along the width and along the length of the plate). In that region of the plate (near the gate) there is a diverging flow during mold filling with coupled shear and elongation effects. Surprisingly at point $C$, in the opposite corner, bubbles are elongated along the width direction (micrograph $\mathrm{C}$ ) but not significantly in the length direction (micrograph C').

The morphology at the plate extremity (micrographs $D$ and $D^{\prime}$ ) is the more heterogeneous, with some pore walls broken. The pressure is minimum during mold filling at that specific position (equal to the gas counter pressure, $2.5 \mathrm{MPa}$, and significantly lower to the saturation pressure, between 6 and $8 \mathrm{MPa}$ ), and foaming may start before the core back process.

This qualitative analysis shows that almost everywhere in the part the skin thickness. A spherical foam morphology is observed in the center of the plate, whereas regions close to the different mold walls where morphology is more disturbed (non spherical shape, orientation, etc...). This could induce local variability for mechanical and thermal properties.

Nevertheless, the mean size of the bubbles remains everywhere in the plate between 80 and 100 microns as pointed out in table 2 and a characteristic bubble size diameter of 90 microns will be considered.

In what follows, a quantitative morphological analysis will be carried out considering only the samples extracted from the central region (Samples A and A'). In section 4.2, the influence of the processing parameters will be analyzed for a given formulation. In section 4.3 , the influence of the formulation of the polypropylene and the type of CBA will be investigated.

\section{2 - Influence of the processing parameters for one formulation}

The influence of the injection time and of the applied Gas Counter Pressure will be successively investigated for PP filled with talc and fibers and CBA 1.

\subsection{1 - Influence of the injection time}

Figure 6 presents the morphology in the center of the plates obtained at different injection times which means at different injection flow rates (group 2, see table 1). Figures $6 \mathrm{a}$ to $6 \mathrm{~d}$ 
correspond to injection times of $0.7 \mathrm{~s}, 0.9 \mathrm{~s}, 1.2 \mathrm{~s}$ and $1.5 \mathrm{~s}$, respectively (tests $2-1,2-2,2-3$ and 2-4).

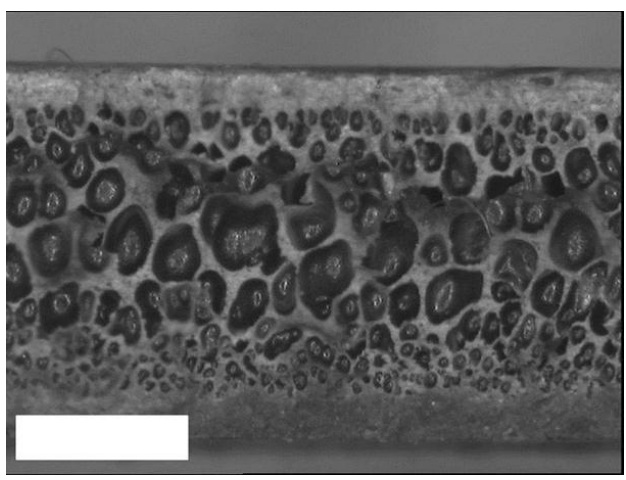

a)

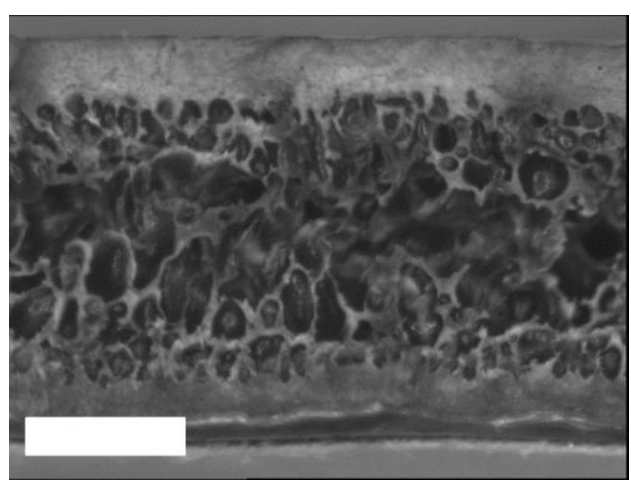

c)

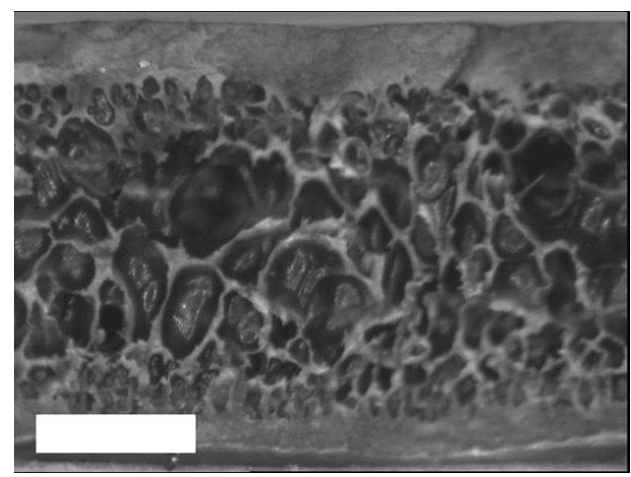

b)

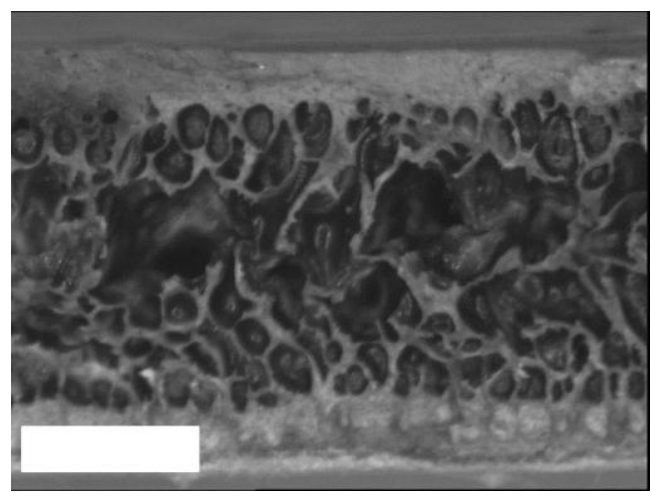

d)

Figure 6 - Influence of the injection time on the morphology of the samples of group 2 (bar scale $1 \mathrm{~mm}$ ) $P P 3(P P+$ Talc + Fibers $)+C B A 1$
a) $0.7 \mathrm{~s}$
b) $0.9 \mathrm{~s}$
c) $1.2 \mathrm{~s}$
d) $1.5 \mathrm{~s}$

The skin thickness remains almost constant but the cell shape becomes less spherical and their size increases when the injection time increases. Cell size presents a growing variability in the thickness, with values between $30 \mu \mathrm{m}$ near the skin, and $150 \mu \mathrm{m}$ in the core. A possible reason to explain the dependence of the morphology with injection time is detailed in figure 7, which shows an approximation of the pressure evolution along the mold length during filling for low and high injection times. 


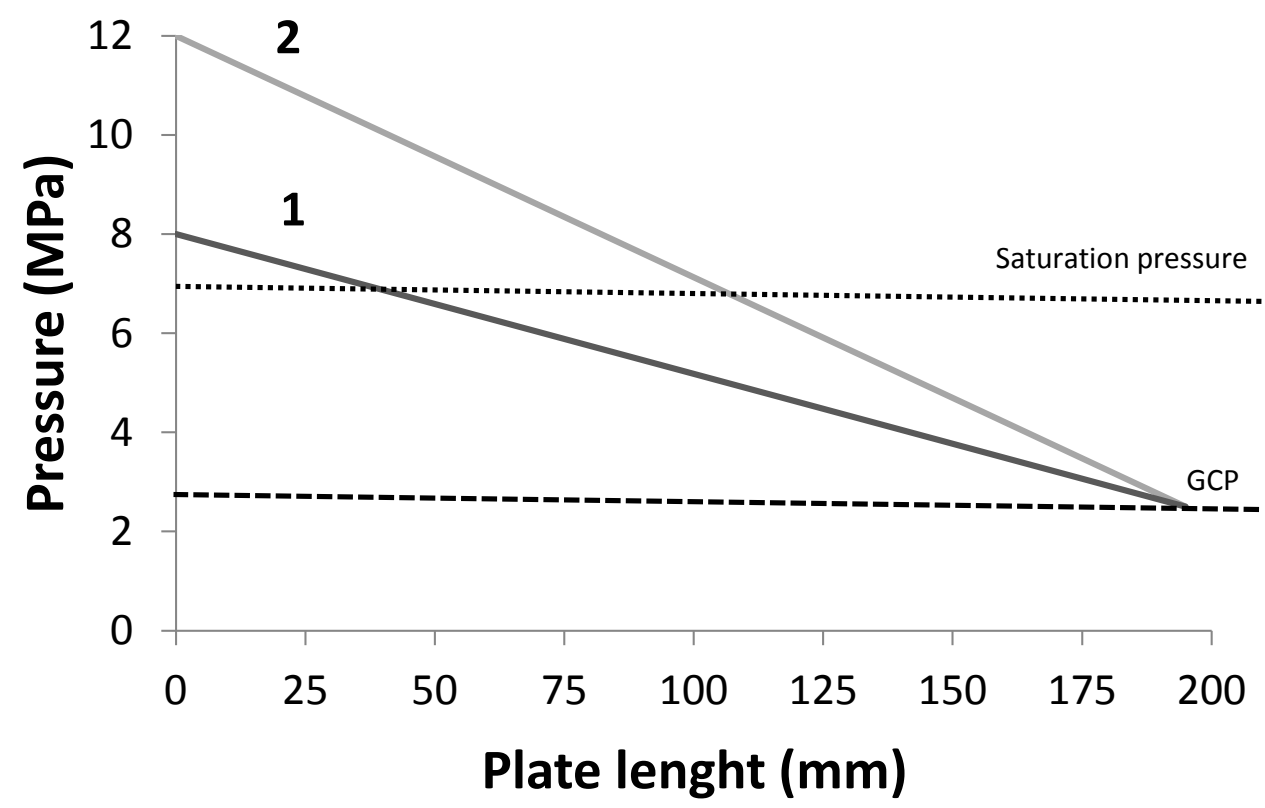

Figure 7- Evolution of the pressure during mold filling for low and high injection times

At high injection times, (curve 1 in figure 7), the pressure on the center of the plate $(x \approx 98 \mathrm{~mm})$ may be less than the saturation pressure and foaming may be initiated. At low injection times (curve 2 in figure 7), the pressure in the middle of the plate is slightly higher than the saturation pressure and no foaming occurs during filling.

Table 3 shows the foam density, the mean equivalent bubble radius and the cell number for the samples injected at different injection times. The variability of the bubble radius is more important than in table 2. Otherwise the value of the foam density $\rho_{F}$ is similar in all the samples, indicating that the core-back opening course is the key parameter to control the foam expansion and the final foam density. In all our tests, the final plate thickness was fixed at $2.5 \mathrm{~mm}$, with a foam density value between 0.53 and $0.58 \mathrm{~g} / \mathrm{cm}^{3}$. Lower core-back opening courses will lead to higher foam density values, and vice versa.

\begin{tabular}{|c|c|c|c|c|c|}
\hline Test & $\begin{array}{c}\text { Injection time } \\
(\mathbf{s})\end{array}$ & $\begin{array}{c}\text { Bubble } \\
\text { count }\end{array}$ & $\begin{array}{c}\boldsymbol{R} \\
(\boldsymbol{\mu m})\end{array}$ & $\begin{array}{c}\rho_{\mathrm{F}} \\
\left(\mathrm{g} / \mathrm{cm}^{3}\right)\end{array}$ & $\begin{array}{c}\mathbf{N}_{\boldsymbol{c}} \\
\left(\mathrm{cm}^{-3}\right)\end{array}$ \\
\hline $2-1$ & 0.7 & 211 & $121 \pm 31$ & 0.53 & $1.43 \cdot 10^{4}$ \\
\hline $2-2$ & 0.9 & 184 & $142 \pm 25$ & 0.55 & $1.02 \cdot 10^{4}$ \\
\hline $2-3$ & 1.2 & 165 & $168 \pm 28$ & 0.54 & $8.78 \cdot 10^{3}$ \\
\hline $2-4$ & 1.5 & 129 & $184 \pm 24$ & 0.58 & $6.97 \cdot 10^{3}$ \\
\hline
\end{tabular}

Table 3 - Morphological parameters of the plates obtained at different injection times

\subsection{2 - Influence of the Gas Counter Pressure}

Figure 8 presents the effect of the Gas Counter Pressure with the formulation (PP-1 + CBA1). For comparison purpose, plates from test 1-1 (1 MPa of GCP) and plates from test 1-3 (2.5 MPa of GCP), were employed, together with one additional test carried out without GCP. The micrographs extracted from the center of each plate (position A) show larger bubbles in the center with a GCP of $2.5 \mathrm{Mpa}$ compared to $1 \mathrm{MPa}$, and smaller sizes near the solid skins similar for both GCPs. Samples injected without GCP (meaning in fact a $0.1 \mathrm{MPa}$ pressure if the air escapes freely) shows a more homogeneous size in the thickness, with a slightly higher average radius ( $97 \mu \mathrm{m} \pm 15 \mu \mathrm{m}$ for the sample injected with $2.5 \mathrm{MPa}$ of GCP and 115 $\mu \mathrm{m} \pm 24 \mu \mathrm{m}$ for the sample injected without GCP). The thickness of the skin without visible bubbles is nearly the same, probably because it is mainly dependent of the solidification rate, 
which does not depend of the GCP. The thickness of the skin without visible bubbles is nearly the same.
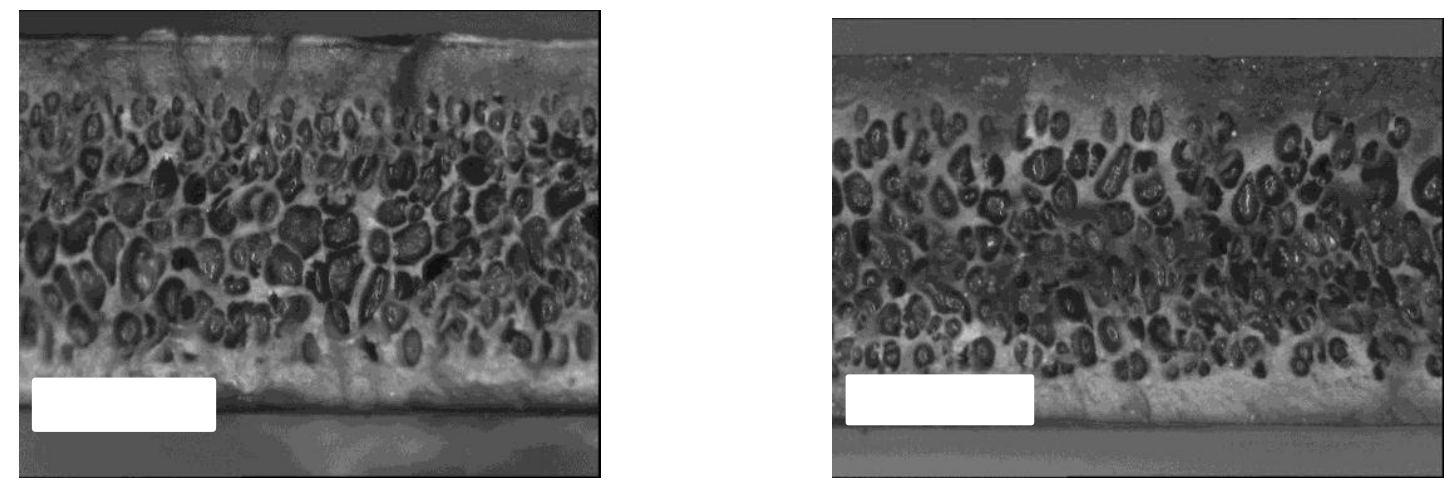

a)

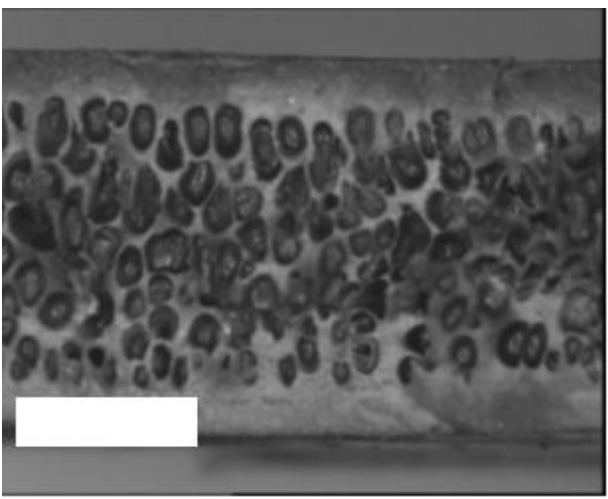

c)

Figure 8-Optical micrographs showing the influence of the Gas Counter Pressure (bar scale $1 \mathrm{~mm}$ ) $P P-1($ Pure $P P)+C B A 1$

$\begin{array}{llll}\text { a) } 2.5 \mathrm{MPa} G C P & \text { b) } 1 \mathrm{MPa} G C P & \text { c) Without } G C P\end{array}$

On the other hand, the surface aspect of the samples is greatly influenced by this Gas Counter Pressure. Figure 9 presents an optical micrograph of the surface aspect of a sample injected with only $0.5 \mathrm{MPa}$ of GCP (test 1-16).

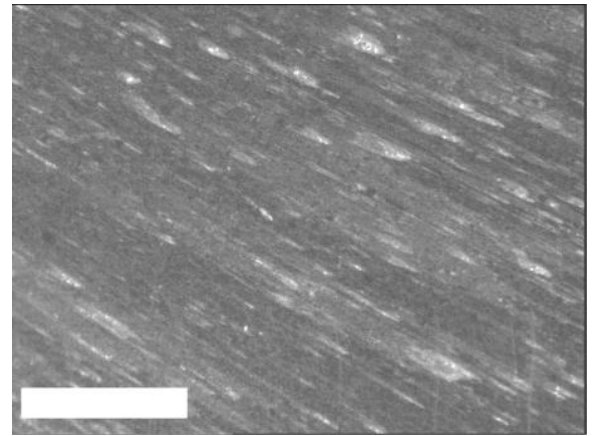

Figure 9- Surface aspect of the an injected sample with 0.5 MPa of GCP (bar scale $1 \mathrm{~mm}$ ) $P P 3(P P+$ Talc + Fibers $)+C B A 2$

White traces are present on the surface when using low values of GCP. SEM/EDX analysis evidences the presence of inorganic residues derived from the foaming agent (sodium bicarbonate) or of particle fillers. In the present work, increasing GCP values above $2 \mathrm{MPa}$ was sufficient to avoid the presence of these surface defects obtaining mirror-faced injected 
samples. In previous works using Physical Blowing Agents (PBA), the GCP values required to obtain a good surface aspect were in the order of $10 \mathrm{MPa}$ [19-21]. In our work with a chemical blowing agent smaller values of GCP are sufficient.

\section{3 - Influence of the formulation}

First, for a given CBA, the three different PPs were investigated (tests 1-2, 1-8 and 1-14 for CBA-1 and tests 1-5, 1-11 and 1-17 for CBA-2). Figure 10a corresponds to PP-1+CBA-1, figure $10 \mathrm{~b}$ to $\mathrm{PP}-2+\mathrm{CBA}-1$ and figure $10 \mathrm{c}$ to $\mathrm{PP}-3+\mathrm{CBA}-1$. In a similar way, figures $10 \mathrm{~d}$ correspond to PP-1+CBA-2, figure 10 e to PP-2+CBA-2 and figure 10 to PP $-3+\mathrm{CBA}-2$.

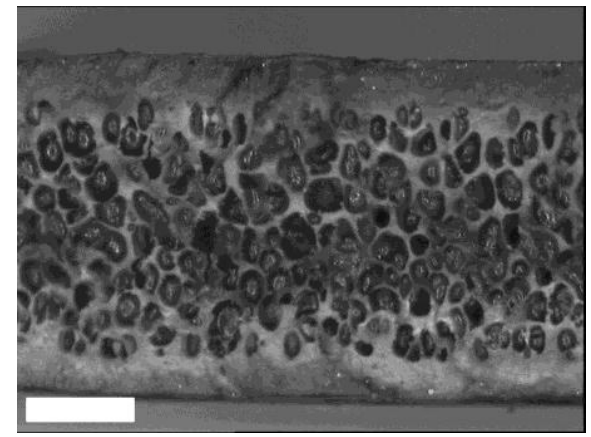

a)

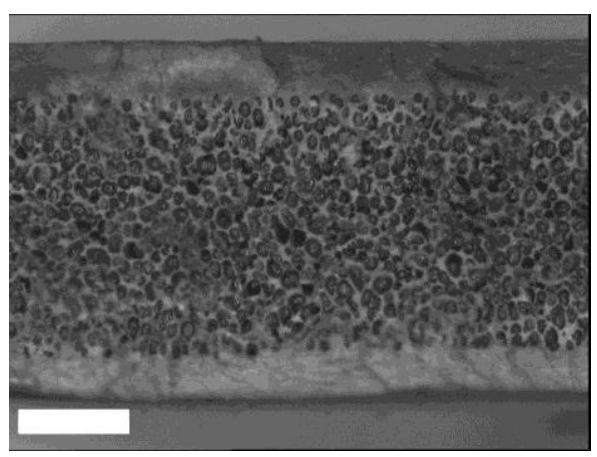

d)

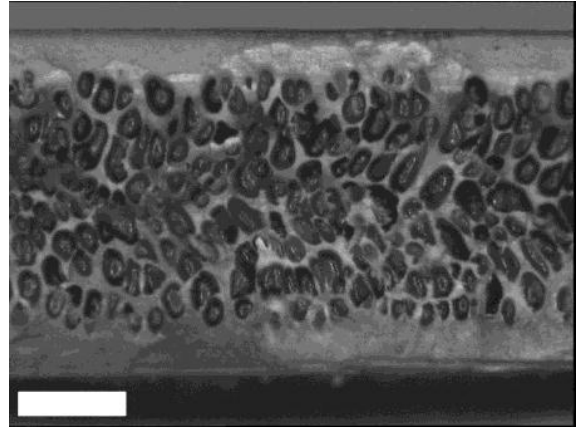

b)

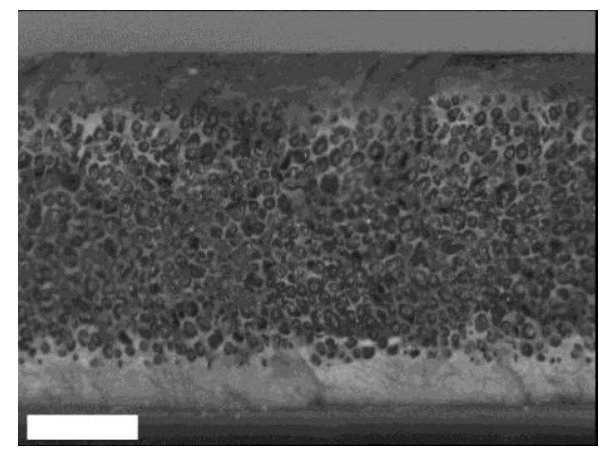

e)

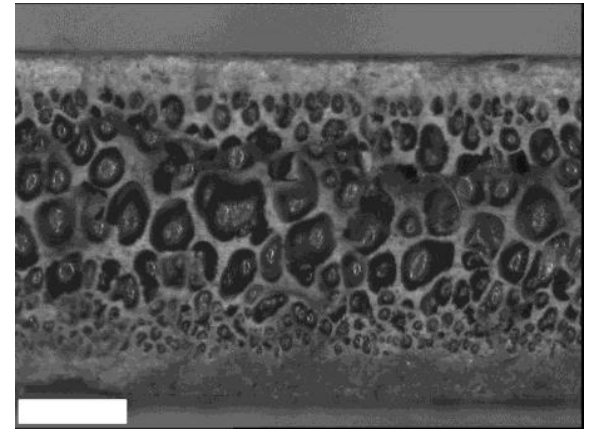

c)

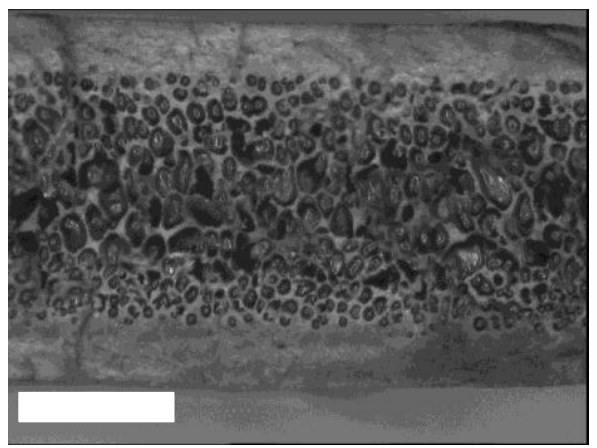

f)

Figure 10 - Optical micrographs showing the influence of the PP formulation (bar scale $1 \mathrm{~mm}$ )

a) Pure $P P+C B A-1$

b) $(P P+T a l c)+C B A-1$

c) $(P P+$ Talc + Fiber $)+C B A-1$

d) Pure $P P+C B A-2$

e) $(P P+T a l c)+C B A-2$

f) $(P P+T a l c+F i b e r)+C B A-2$

The final density of the plates was about $0.60 \mathrm{~g} / \mathrm{cm}^{3}$ in all situations, which indicates a foaming expansion ratio of 1.5. All the foamed samples present a typical solid outer skin, with a total thickness between $700 \mu \mathrm{m}$ and $800 \mu \mathrm{m}$. However, it can be clearly seen that the foam morphology and cell radius of the samples depend strongly on the formulation employed.

The homogeneity of the pore morphology is mainly controlled by the presence of fillers, specially the magnesium fibers. Samples obtained from talc and magnesium filled polymer PP-3 (figures 10c and 10f) present an inhomogeneous cellular structure, with larger cells in 
the core. On the other hand, samples obtained from talc filled polymer PP-2 and pure polymer PP-1 (figures 10a ,10b, 10d, 10e) present a more homogeneous structure.

Samples injected with CBA-2 present a lower cell radius than samples injected with CBA-1. On the other hand, the foam density is equivalent, and as seen in figure 1, the quantity of gas created by CBA-2 is more important than the quantity of gas created by CBA-1. The influence of the chemical foaming agent can be explained from DSC curves. Both CBAs present an endothermic behavior, which indicates that the gas generation reduces the temperature of the surrounding polymer. The enthalpies of both decomposition reactions are $2206 \mathrm{~J} / \mathrm{g}$ and $3121 \mathrm{~J} / \mathrm{g}$ for CBA-1 and CBA-2, respectively. This indicates that the polymer temperature decrease around the growing gas bubble is higher for the CBA-2, leading to lower gas pressures inside the bubble (perfect gas law).

Table 4 presents the average bubble radius $\bar{R}$, the foam density $\rho_{F}$ and the number of cells $N_{C}$ for each type of CBA and PP employed, indicating that bubble radius is mainly controlled by the chemical foaming agent and the formulation of PP, especially the presence of fibers.

\begin{tabular}{|c|c|c|c|c|c|c|}
\hline \multirow{2}{*}{$\boldsymbol{P P}$} & CBA & Test & $\begin{array}{c}\text { Bubble } \\
\text { count }\end{array}$ & $\begin{array}{c}\overline{\boldsymbol{R}} \\
(\mu \mathrm{m})\end{array}$ & $\begin{array}{c}\rho_{\mathrm{F}} \\
\left(\mathrm{g} / \mathrm{cm}^{3}\right)\end{array}$ & $\begin{array}{c}\mathbf{N}_{\boldsymbol{c}} \\
\left(\mathrm{cm}^{-3}\right)\end{array}$ \\
\hline \multirow{2}{*}{1} & 1 & $1-2$ & 164 & $74 \pm 8$ & 0.53 & $3.75 \cdot 10^{5}$ \\
\cline { 2 - 7 } & 2 & $1-5$ & 331 & $41 \pm 3$ & 0.55 & $8.58 \cdot 10^{5}$ \\
\hline \multirow{2}{*}{2} & 1 & $1-8$ & 171 & $77 \pm 9$ & 0.54 & $3.68 \cdot 10^{5}$ \\
\cline { 2 - 7 } & 2 & $1-11$ & 378 & $38 \pm 3$ & 0.51 & $9.92 \cdot 10^{5}$ \\
\hline \multirow{2}{*}{3} & 1 & $1-14$ & 145 & $96 \pm 25$ & 0.59 & $4.43 \cdot 10^{4}$ \\
\cline { 2 - 7 } & 2 & $1-18$ & 198 & $51 \pm 11$ & 0.53 & $6.23 \cdot 10^{5}$ \\
\hline
\end{tabular}

Table 4 - Morphological parameters of the plates obtained with different formulations

Bledzki et al [15] obtained more important values for the cell radius (about $150 \mu \mathrm{m}$ ) using PBA injection process combined to GCP and core-back. However the cell density is significantly lower $\left(\mathrm{N}_{\mathrm{c}} \approx 10^{3} \mathrm{~cm}^{-3}\right)$, and the cellular structure is not homogeneous. Kotzev et al. [16] investigated the classical injection foaming process of LDPE using GCP and CBA, obtaining cells with diameters between $300 \mu \mathrm{m}$ and $400 \mu \mathrm{m}$, but also with a lower cell density, and an irregular cellular structure. Classical CBA injection foaming process has been investigated by Bociaga et al. [10], in which HDPE is injected and foamed using different quantities of CBA. Foamed samples present low values of cell density $\left(\mathrm{N}_{\mathrm{c}} \approx 10^{3} \mathrm{~cm}^{-3}\right)$, with pore diameters in the range of $100 \mu \mathrm{m}$. The PBA foaming process of amorphous polymers, especially PS, has been analyzed by Li et al. [26] with different values of GCP (up to $6 \mathrm{MPa}$ ) but without core-back. The obtained structure has also a low value of cell density, and cell diameters are about $50 \mu \mathrm{m}$. Compared to the results obtained in this work, it is clear that the combination of CBA, GCP and core-back process can lead to more homogeneous cell structures and lower cell diameters.

At a first glance, one may believe obtaining cell sizes decreasing from the core to the skin of the foamed sample. This is observed for example figure $9 \mathrm{c}$ and $9 \mathrm{f}$, even if it less marked in other micrographs. This could be explained from thermal conditions. In the core of the plate, 
the cooling rate is low and, as a consequence, the crystallization temperature is high (near the thermodynamic equilibrium temperature). Near the plate walls the cooling rate is much more important and the crystallization temperature is far below the thermodynamic equilibrium temperature. So there is a balance between cooling time (which is much shorter near the skin than in the core) and crystallization temperature (which is higher in the core than near the skin) which could explain a surprising bubble size homogeneity observed for some PP formulations, except in the closed outer skin region.

\section{Conclusions}

In the present work, a morphological analysis of microcellular injected polypropylene using CBA and a combination of core-back and GCP processes has been carried out. It has been observed that the PP formulation and CBA has a strong influence on the final foam morphology. Samples injected from neat PP or talc charged PP presented an homogeneous structure (less than $5 \%$ of dispersion in the average bubble radius along the plate thickness), whereas adding magnesium fibers results in heterogeneities (dispersion values between $40 \%$ and $50 \%$ ). Two different types of CBA were investigated, based on citric acid and sodium bicarbonate. It was observed that CBA with both citric acid and sodium bicarbonate increases the bubble radius of about $100 \%$ as compared to CBA based on citric acid only.

Concerning the influence of the processing parameters, the GCP influences the surface aspect of the samples, a decrease in the flow rate leads to a slight increase of the bubble radius.

Experimental results were compared to the literature, showing that using CBAs combined to moderate GCP values and core-back process provide low density samples $\left(0.5 \mathrm{~g} / \mathrm{cm}^{3}\right)$, with a more homogeneous structure than classical foaming injection processes. So it is possible to control the foam structure by playing on the PP formulation (fillers and fibers), the type of CBA and the injection parameters.

\section{References}

1. J. Xu, L-S. (Tom) Turng. Microcellular injection molding ISBN: 978-0-470-46612-4, Wiley International, (2010).

2. A. Mechraoui, B. Riedl and Denis Rodrigue. J. of Cellular Plastics, 47, 115, (2011).

3. J.A. Reglero Ruiz, M. Pedros, J-M. Tallon and M. Dumon. J. of Supercritical Fluids, 58, 168, (2011).

4. A.K. Bledzki and O. Faruk, Macromol. Mater. Eng., 291, 1226, (2006).

5. D. Rodrigue and R. Barzegaril R. Polym. Eng. Sci., 48, 1600, (2008).

6. D.L. Tomasko, A. Burley, S-K. Yeh, L. Feng, K. Miyazono, S. Nirmal-Kumar, I. Kusaka and

K. Koelling. J. of Supercritical Fluids, 47, 493, (2009).

7 - www.trexel.com

8. C. B. Park and N. P. Suh.. Polym. Eng. Sci., 36, 34, (1996). 
9. A. H. Behravesh, C. B. Park, L. K. Cheung and R.D. Venter. J. of Vinyl \& Additive Tech. 2, 349, (1996).

10. E. Bociaga and P. Palutkiewicz. Polym. Eng. Sci., 53, 780, (2013).

11. A. K. Bledzki and O. Faruk. J. of App. Polym. Sci., 97, 1090, (2005).

12. C.A. Villamizar and C.D. Han. Polym. Eng. Sci., 18, 699, (1978).

13. S.W. Cha and J.D. Yoon. Polym. Plastic Techn Eng., 44, 795, (2005).

14. M.C. Guo, A. Santoni, M.C. Heuzey and P.J. Carreau. J. of Cellular Plastics. 43, 273, (2007).

15. A.K. Bledzki, J. Kuehn, H. Kirschling and W. Pitscheneder. Cell. Polym. 27, 90, (2008).

16. G. Kotzev, S. Djoumaliisky M. Krasteva, M. Iliev, E. Pérez and M.L. Cerrada. Macrom. Materials and Eng., 292, 769, (2007).

17. D. Jahani, A. Ameli, M.R. Barzegari, C.B. Park and H. Naguib. Materials and Design, 53, 20, (2014).

18. R. Pantani. J. of Mat Process. Tech. 214, 1665, (2014).

19. S.C. Chen, W-H Liao and R-D.Chien. Int. Comm. Heat Mass Transf, 39, 971, (2012).

20. S.C.Chen, P.S. Hsu and S.S. Hwang. J. of Applied Polym Sci, 127, 4769, (2013).

21. S.C. Chen, P.S. Hsu and Y.W. Lin. Int. Polym. Processing, 26, 275, (2011).

22. J. Lee, L.S. Turng, E. Dougherty and P. Gorton. Polymer, 52, 1436, (2011).

23. J.A. Reglero Ruiz, M. Vincent, J-F Agassant, T. Sadik, C. Pillon and C. Carrot. Accepted, Polym. Eng. Science, PES 14-1046.R1, (2014).

24. Z. Lei, H. Ohyabu, Y. Sato, H. Inomata and R. Smith. J. of Supercritical Fluids, 40, 452, (2007).

25. R. Gosseling and D. Rodrigue. Polymer testing, 24, 1027, (2005).

26. S. Li, G. Zhao, G. Wang, Y.Guan and X Wang. J. of Cellular Plastics, 50, 415, (2014).

\section{Acknowledgments}

Authors would like to acknowledge SUMIKA Polymer Compounds France for providing the raw materials. Financial support FUI (PLUME Project) is also gratefully acknowledged. TGA experiments have been performed at the University Jean Monnet of Saint-Etienne (FRANCE). 